\title{
Bar Coding-Not Just in the Supermarket Anymore
}

\author{
Douglas Sellinger
}

$\mathrm{B}$ efore I started to write this presidential officer's report, I decided to fuel up with a good cup of coffee. I have invested in a Tassimo coffee maker and keep a large variety of T DISC coffees, teas, and hot chocolate on hand. The goal of this coffee system is to dispense the same high-quality beverage each and every time. In addition to my home device, I also have access to a Tassimo coffee maker in my hospital pharmacy. The "unit-ofuse" T DISCs with bar-coding allow me to replicate a perfect cup of coffee every time, at home or at work. With bar code technology and a couple of forcing functions (to prevent me from inserting the T DISC upside down), I can be a master of the hot beverage, always having the right blend of coffee, the right amount of water, and the proper brewing time. Barcoding has become not only ubiquitous but required in our everyday lives - with the possible exception of our hospitals and hospital pharmacies.

The Hospital Pharmacy in Canada 2009/2010 Report indicated that $99 \%$ of hospitals with 50 beds or more had a pharmacy information system, and $80 \%$ of these systems provided some level of clinical decision support (see www. lillyhospitalsurvey.ca/hpc2/content/2010_report/chapter_f\%20 .pdf). However, only $8 \%$ of hospitals reported using bar-coding to verify drug selection before administration to patients. The most significant uses of bar-coding in hospital pharmacy systems were to verify medications for stocking in automated repackaging machines $(69 \%)$ and to verify stocking of automated dispensing cabinets (50\%). According to the report, use of bar-coding can reduce dispensing error rates by over 30\% and the potential rate of medication incidents by more than $60 \%$, yet most hospital pharmacies in Canada have not yet fully embraced the power of bar codes.

In particular, although we are starting to use bar-coding in the hospital pharmacy supply chain to improve efficiency, we have not yet tackled the medication safety advantages for patients that are available through automated bedside verification of medication, patient, and provider. To realize the potential error reductions indicated by the Hospital Pharmacy in
Canada Report, we need to incorporate automation into our application of the " 5 rights of medication administration" for all of our patients. We need to take advantage of the power of bar codes to see things that our own eyes may miss or our brains re-interpret.

In response to this

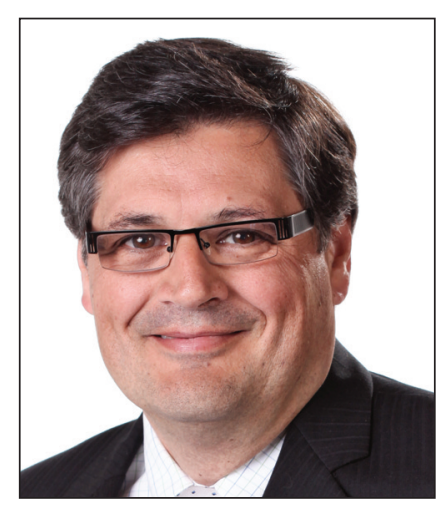
need, the Institute for Safe Medication Practices Canada and the Canadian Patient Safety Institute have spearheaded the Canadian Pharmaceutical Bar Coding Project (see www.ismpcanada.org/barcoding/). This project has identified 2 major concerns with the current medication supply chain, a system based on human identification methods: (1) assurance of medication safety for the patient and (2) efficiency and accuracy of the supply chain. The "Joint Technical Statement on Pharmaceutical Automated Identification and Product Database Requirements", which was updated and released in February 2012, provides guidance on creating the tools required to improve supply chain efficiency and enhance medication safety.

So now I can enjoy my perfectly prepared cup of coffee while contemplating our health region's complex medicationuse system and considering how bar codes could enhance medication safety and improve the efficiency of providing medications to patients.

Douglas Sellinger, BSP, MALT, is the President and External Liaison for the Canadian Society of Hospital Pharmacists. 